\title{
Isolierter Bruch der Tabula interna mit schwerer Hirnzertrümmerung bei Nackenstreifschuß.
}

Von Assistenzarzt Dr. Johannes Volkmann, im Felde.

So häufig ausgedehnte Splitterungen der inneren Tafel des knöchernen Schädeldachs bei gleichzeitiger Verletzung der äußeren sind, so selten werden isolierte Brüche der Interna beobachtet. Wie Brandes ${ }^{1}$ ) neulich erwähnt, haben weder er noch Hohlbeek bei einem großen Material sie gesehen, ja Proku ni n hält sie überhaupt nur für möglich, während anderseits Treves und Rosanow seinerzeit darüber berichtet haben (die Arbeit ist mir nicht zugänglich) und Gussew sie sogar für häufiger als isolierte Frakturen der Externa ansieht. Auch W. v. Oettingen spricht nur kurz bei der Behandlung der Prellschüsse davion, und Tilmann schreibt im Lehrbuch der Chirurgie von Wullstein und Wilms: „So kann ein Schlag mit einer Faust die getroffene äußere Lamelle intakt lassen, dagegen auf der inneren eine Fissur bewirken."

Da lohnt es sich wohl, einen so seltenen Fall wie den von uns beobachteten $z u$ schildern, der noch dazu durch die sonderbare Art des Verletzungsvorgangs, die ausgedehnten Klein- und Großhirnzertrümmerungen und einen überraschend schnellen tödlichen Verlauf ausgezeichnet war.

Aus der Krankengeschichte und dem Sektionsprotokoll gebe ich Folgendes wieder:

Vorgeschichte: Verwundet am 28. April 1916 früh im Kampfgraben durch Infanteriestreifschuß. Sofort Erblindung.

Bef und am 28. April: Kräftiger, junger Mann von gesunder Farbe. Patient antwortet klar auf alle Fragen, weiß aber über den Hergang der Verwundung nichts auszusagen, klagt über etwas Schwindel und sieht nur hell und dunkel, ohne einzelnes unterscheiden zu können. $\mathrm{Pu}$ pillen ziemlich eng, reagieren aber auf Lichteinfall beiderseits gleich. Bewegungen der Augäpfel frei, kein Nystagmus. Gehör gut.

Behandlung: Operation unter $2 \%$ iger Novokain-Suprarenineinspritzung. Ausschneiden der Wundränder und Erweitern der Wunde bis in die Tiefe auf den Knochen, sodaß man die Schädelkapsel weithin betrachten kann. Nirgends eine Periostverletzung oder Infraktion. Naht bis auf einen Jodoformgazestreifen in dem einen Wundwinkel.

Verlauf: Am 29. April sah ich den. Patienten zum ersten Male. Er ist jetzt dauernd außerordentlich unruhig, schlägt um sich, läßt sich

1) M. m. W. $1916 \mathrm{Nr} .21$ 
im Bett kaum halten, dabei meist etwas benommen. Verbandwechsel zeigt an der Wunde nichts Besonderes, der Jodoformgazestreifen wird entfernt und ein Stärkebindenverband angelegt. Erscheinungen von seiten anderer Organe nicht festzustellen, doch ist eine Untersuchung sehr schwierig. Nur eine ganz geringe Gleichgewichtsstörung beim Stehen, sonst keine Kleinhirnsymptome. Kein Druckpuls. Morphium 0,02, Skopolamin 0,0003 .

30. April. Patient war während der Nacht ruhig. Dagegen rèagiert er morgens plötzlich auf nichts mehr und hat beréits Trachealrasseln. Rechte Pupille größer als linke. Puls klein, flach, unrègelmäßig. Es wird, da in diesem Zustande von einer Operation abgesehen werden muß, der Versuch einer intrakardialen Injektion von Strophanthin $0,0005: 10,0$ physiologischer Kochsalzlösung gemacht. Nach wenigen Minuten ist der Puls voll, kräftig, regelmäßig und nur wenig beschleunigt. Trotzdem nach einigen Stunden weiterer Verfall und Tod um $12 \mathrm{Uhr}$ mittags.

Klinische Diagnose: Streifschuß im Nacken mit Contusio cerebri.

Leichenöff nu ng am 1. Mai vormittags. Aeußeres: Große männliche Leiche von blasser Hautfarbe, reichlichem Fettpolster und gut entwickelter Muskulatur. Totenflecke an den abhängigen Teilen, Totenstarre. Im vierten linken Zwischenrippenraum neben dem Brustbeinrand eine kaum mehr sichtbare Einstichöffnung. Am unteren Teil des Hinterkopfes am Uebergang in den Nacken eine etwa $10 \mathrm{~cm}$ lange, von der Basis des rechten Warzenfortsatzes noch nach links über die Mittellinie reichende, linear bis auf den einen Wundwinkel genähte Operationswunde. Nach Auftrennen der Nähte läßt sich dieWunde so weit atiseinander ziehen, daß der Hinterhauptknochen weithin bloßliegt, oben noch eben bis an die Protuberantia occipitalis externa. Nirgends eine Periostläsion oder Bruchlinie, keine Impression, kein Geschoß zu finden. — Schädel : Eröffnung in gewöhnlicher Weise unter Schonung der Verletzungsstelle am Hinterkopf. Knöchernes Schädeldach von außen ohnekrankhaften Befund. Beim Versuch, es vorsichtig abzunehmen, zeigt sich die harte Hirnhaut so fest mit dem Knochen verwachsen, daß sie mitsamt dem Schädeldach abgelöst werden muß, wobei aber beim Herumklappen die Dura in ihrem hinteren Teil intakt gelassen wird. Nachdem man sieht, daß sie unverletzt ist, wird sie auch hinten durchtrennt und mit dem Schädeldach entfernt. Knochen ohne Befund, harte Hirnhaut zeigt auf der Höhe des Scheitels reichlich Pacchionische Granulationen, die Sinus enthalten wenig flüssiges Blut. Die weichen Hirnhäute sind glänzend, nicht getrübt, enthalten keine abnorme Flüssigkeit, die Gefäße sind gut gefüllt. Die Pia läßt sich glatt abziehen. Windungen normal ausgebildet, nirgends abgeplattet. Schon jetzt bei der Lage in der. Schädelkapsel sieht man, daß beide Großhirnhemisphären gerade über dem Tentorium cerebelli je einen $4 \mathrm{~cm}$ langen Zertrümmerungsherd zeigen, um den das Gewebe schmutzig verfärbt, gequetscht und etwas blutig durchtränkt ist. Nach Herausnahme des ganzen Gehirns werden an beiden Kleinhirnhemisphären über den hintersten Windungen zwei den Stellen an den Großhirnhemisphären entsprechende Zertrümmerungsherde sichtbar, etwa von der gleichen Ausdehnung. Auf dem Schnitt bietet die Hirnsubstanz nirgends einen krankhaften Befurd, nur um die Zertrümmerungsherde, die etwa $11 / 4 \mathrm{~cm}$ in die Tiefe bis in die weiße Substanz reichen, ist das Gewebe gelblich verfärbt und blutreicher. Nach Abziehen der harten Hirnhaut in der hinteren Schädelgrube zeigt sich, $\mathrm{da} ß$ an der Protuberantia occipitalis interna am Zusammenfluß der großen Blutleiter zwei je etwa $1,5 \mathrm{qcm}$ große, flache Absprengungen der Tabula interna bestehen. Dỉese Stücke lassen sich leicht aus ihrem Bett herausheben, soda $\beta$ dann dunkles, geronnenes Blut in der Diploë sichtbar wird. Auf einem durch diese Gegend geführten Sägeschnitt sieht man deutlich, daß die Tabula externa intakt ist. Auch hier war die Dura nicht verletzt. - Brusthöhle: Im linken vierten $Z$ wischenrippenraum innen sieht man von der äußeren Einstichöffnung nichts, Gefäße jedenfalls nicht verletzt. Im Herzbeutel Einstich nicht mehr nachweisbar, dagegen leichte, subseröse Blutungen von etwa $1 / 2 \mathrm{qcm}$ Größe an der Vorderseite des rechten Herzens, $1 \mathrm{~cm}$ von der vorderen Kante und $4 \mathrm{~cm}$ von der Spitze entfernt. Herz größer als die Faust, gut zusammengezogen, sonst ohne Befund. Im Inneren von der Einstichöffnung nichts mehr $\mathrm{zu}$ sehen. Beide.Lungenränder berühren sich fast vorn in der Mittellinie, rechts und links leichte Verwachsungen, auf der Oberfläche vereinzelte frische Fáserstoffauflagerungen und hellgelbe, stärker geblähte Stellen, die sich gegen die sonst blaurote Umgebung deutlich abheben. Konsistenz gleichmäßig zähelastisch ohne besonders derbe, umschriebene Stellen. Auf dem Schnitt ist das Gewebe, besonders in den abhängigen Teilen, sehr blutreich, eine trübgelbe, schaumige Flüssigkeit läßt sich ausdrücken. In den Verästelungen der Bronchien vereinzelt Speisereste. Bauch ohne Befund.

Pathologisch-anatomische Diagnose: Operierter Weichteilsstreifschu $\beta$ am rechten Nacken; zwei Absplitterungen der Tabula interna an der Protubarantia occipitalis interna; Zertrümmerung beider Großund Kleinhirnhemisphären. Beginnende Bronchopneumonie.
Todesursache: Groß- und Kleinhirnzertrümmerung, beginnende Bronchopneumonie.

Soweit der klinische Befund und das Sektionsergebnis. Nun noch einige Worte aur Epikrise. Es handelt sich also um einen jener Falle von Streifschuß mit Fornwirkungen, wie sle auch Perthes mehrfach beschrieben hat. Da bei blo Ben Weichteilschïssen des Koples Brschtitterungen hä̈ufigg beolbachtet werden, ähnlich wie beim Rutckentilark; ist ja bekannt; so ausgedehnte Verletzungen wie in diesem Fall, wo sich in beiden Klein- und Großhirnhemisphären ausgedehnte Zertrümmerungsherde fanden, sind aber doch wohl seltener. Jedenfalls habe ich in der. mir zugänglichen, ziemlich umfangreichen Literatur nirgends Angaben darüber gelesen. Nur Hölscher, der in einem Vortrag in Lille über die auf meine Anregung hin gemachten Erfahrungen über primäre Naht bei Schädelschüssen berichtete, erwähnt eine übrigens auch nicht in vivo diagnostizierte Beobachtung.

Wenn nun zur Erklärung der dabei wirksamen mechanischen Vorgänge in vielen Füllen die einfache Annahme genügt, daß das Gehirn der von hinten nach vorn einwirkenden Druckspannung nicht entsprechend in einer dazu senkrechten Seitenrichtung ausweichen konnte, so darf man doch hier für die auffallend sohwere Z̈ertrtummerung noch nach einer besonderen Ursache suchen, die sich wohl ganz ohne Kunstelei in den festen Verwachsungen der harten Hirnhaut auf der Höhe der Schädelwölbung finden läBt: Wie es uns kaum tnöglich war, die Dura vợ Knochen lösen, so hat sie dem rasch aúf sië ausgeübten Druck des nach innen eingebogenen Hinterhauptbeins nieht nachgegeben, sich vielmehr fest angespannt und dadurch die Hrschüttérung mit besoliderer Wucht weitergetragen. Den Bruchstücken selbst ist keine hervor̈ragiendè Aufgabe zugefallen, sie lagen, ohne die Dura verletzt ma haben, in dem Bett, aus dem sie herausgerissen waren, durch eine ältere Blutung deutlich gegen die Umgebung abgehoben, zum Teil mit dem Periost noch in $\mathrm{Zu}$ sammenhang stehend. Wie wir uns dabei den Bruchmechanismus selbst zu erklären haben, ist ja nicht schwierig: durch das vorbeifliegende Geschoß wurde auf die äußere Tafel eine beträchtliche, durch die starken, dazwischen gelagerten Weichteilmassen potenzierte Druckspannung ausgeübt, die sich, wenn wir die drei Schichten der Hirnschale nicht als ein festes, innen und außen gleiche Verhältnisse bietendes System auffassen, eben nicht in der äußeren Tafel oder Diploë erschöpfte, sondern an der spröderen, inneren dureh die Abplattung noch so kräftig wirkte, daß eine mächtige Zugspannung entstand, der die einzelnen Knochenelemente trotz ihrer Elastizität-nicht standhielten, soda B es zum Bruch kam, obwohl sonst eine Verstärkung der. Krümmung eher zur Fraktur führt als eine Abflachung ( $Z$ uppinger-Christe $n$ ):

Haben wir uns so die theoretischen Grundlagen unseres Falles klar gemacht, so reiht sich die praktische Frage an: Hätte man hier noch therapeutisch etwas versuchen sollen 'oder überhaupt können, etwa eine Entlastung des Gehirns? Nun, abgesehen davon, daß die Obduktion uns später recht gab, schien mir wenigstens in dem Augenblick, wo ich den Patienten zuerst sah, ein Eingriff aussichtslos, zumal auch hier, wie ja meistens, die rein lokalen Ausfallserscheinungen durch die Unruhe, Bewußtlosigkeit und Aspirationspneumonie verschleiert waren. Hätte man vielleicht, aus der Blindheit auf die Fissura calcarina als Sitz der Zertrümmerung oder (trotz des fehlenden Druckpulses) eines Blutergusses schließend, dort eröffnet und das Kleinhirn, für dessen Verletzung die Symptome nur wenig sprachen, in Ruhe gelassen, dann wären gerade die schwersten Herde nicht entlastet worden. Auch eine intrakardiale Injektion, über die wir auf Grund unserer Erfahrungen in nächster Zeit berichten werden, konnte darum, obwohl im Augenblick von Erfolg begleitet, am schließliohen. Ausgang nichts ändern.

So handelte es sich unen therapeutisch unbefriedigenden, wenn auch theoretisch sehr interessanten Fall, wie er in solcher Art vielleicht häufiger bei Verschüttungen oder anderen rasch tödlichen Verletzungen vorkommt, aber nur selten aufgedeckt werden kann. 